\title{
USING MOBILE AND STATIONARY EYE TRACKING TO BETTER UNDERSTAND CONSUMER SHELF PERCEPTION
}

\author{
USO DE RASTREADORES OCULARES MÓVILES Y FIJOS PARA ENTENDER COMO LOS \\ CONSUMIDORES PERCIBEN LAS ESTANTERÍAS
}

\author{
Jutatip Kastner-Jamsawang ${ }^{\mathrm{a}}$ Udo Wagner $^{\mathrm{b}}$ \\ Classification: Empirical paper - research \\ Received: July 7, 2020 / Revised: August 30, 2020 / Accepted: November 1, 2020
}

\begin{abstract}
Shelf perception is vital for both manufacturers and retailers, as they attempt to satisfy consumer needs and to optimize their profits. On the other hand, consumers have to deal with a vast number of products offered in a modern supermarket and might be confronted with difficulties accomplishing their choice of products. This paper focuses on customer perspective and aims to gain further insights and a profound understanding of on-shelf merchandising, especially visual attention, visual perceptions, and purchase intention of products positioned on the supermarket shelves. After providing an overview of the extant literature, this article reports on four empirical studies: a lab study using a stationary eye tracker, a lab study and field studies in supermarkets of two different retail chains, all using a mobile eye tracker. The research agenda deals with perceptions of horizontal and vertical shelf positions, the "eye level is buy level" theory, and the number of shelf facings. We also consider the impact of walking direction on shelf perception. The combination of different research settings and different measurement instruments corroborates the external and internal validity of the findings, which are relevant for theory and practice.
\end{abstract}

Keywords: shelf perception, eye tracking, visual attention, supermarket shelves, shelf positions, shelf facings

\section{Resumen}

La percepción de la estantería es vital tanto para los fabricantes como para los minoristas, ya que intentan satisfacer las necesidades de los consumidores y optimizar sus ganancias. Por otra parte, los consumidores tienen que lidiar con una gran cantidad de productos que se ofrecen en un supermercado moderno y pueden enfrentarse a dificultades para lograr la elección de sus productos. Este estudio se centra en la perspectiva del cliente y tiene como objetivo obtener más conocimientos y una comprensión profunda de la comercialización en los estantes, especialmente en la atención visual, las percepciones visuales y la intención de compra de los productos colocados en los estantes de los supermercados. Después de proporcionar una descripción general de la literatura existente, este artículo informa sobre cuatro estudios empíricos: un estudio de laboratorio con un rastreador ocular fijo, un estudio de laboratorio y estudios de campo en supermercados de dos cadenas minoristas diferentes, todos con un rastreador ocular móvil. La agenda de investigación se ocupa de las percepciones de las posiciones de los estantes horizontales y verticales, la teoría de que "el nivel de los ojos es el nivel de compra" y el número de niveles el de los estantes. También consideramos el impacto de la dirección de la marcha en la percepción de la plataforma. La combinación de diferentes escenarios de investigación y diferentes instrumentos de medición corrobora la validez externa e interna de los hallazgos, que son relevantes para la teoría y la práctical.

Palabras clave: percepción de los estantes, seguimiento ocular, atención visual, estantes de los supermercados, posiciones de los estantes, niveles de los estantes

a University of Vienna, Vienna, Austria. Email: Jutatip.Kastner.J@gmail.com. Corresponding author.

b University of Vienna, Vienna, Austria. Email: Udo.Wagner@univie.ac.at 


\section{Introduction}

In retailing, one of many challenges sellers and manufacturers face is the allocation of shelf space. Both, retailers and manufacturers must ensure that their merchandise is noticed and consequently purchased, or as Wedel and Pieters $(2008$, p. 2) put it, "Seeing is believing and believing is buying". Their objectives, however, do not coincide. Manufacturers' goals are to maximize sales and profits of their specific products; they strive for favourable and sufficient shelf-space for their own brands. Retailers, contrariwise, maximize category sales and profits (independently of individual brands) and, therefore, try to optimize the allocation of shelf space across the entire assortment. Merchants need to arrange products and product categories in a way that attracts the consumers' attention and encourages them to purchase plenty and frequently (Kastner, 2019).

There is a long tradition of literature dealing with this topic (e.g., Frank \& Massy, 1970), but interest greatly increased at the beginning of the $21^{\text {st }}$ century, with special interest conferences, technological development of eye tracking devices, and the publication of Wedel and Pieters' (2008) book on visual marketing. However, with respect to shelf perception studies (mainly based on survey or sales data), inconclusive or contradictory findings have been reported. The seminal paper of Chandon et al. (2009) used stationary eye tracking and introduced this technology to research shelf allocation in a laboratory setting. However, there were two shortcomings: first, restricting the analysis to a stationary setting neglects the dynamic component and, thus, potential differences when shoppers are walking around within the store; second, a laboratory setting might overemphasize experimental conditions, which somewhat limits the external validity of the findings.

This research builds on the conclusions of Chandon et al. (2009), but aims to incorporate shoppers' movement and dynamic viewing patterns. In addition, we attempt to increase the external validity by conducting field studies. We investigate the effects of both a product's position on the shelf (with respect to top, eye, touch or bottom level, and left, centre, or right location) and its number of facings ${ }^{1}$ on shoppers' visual attention, perception, and purchase intention; importantly, we account for walking direction (i.e., whether the customer approaches the shelf from the left or right side). In line with Chandon et al. (2009), we concentrate on the customer perspective

1 Some literature refers to facings as the shelf space assigned to a stock keeping unit (abbreviated as SKU in the sequel); the latter also depends inherently on the size of the product, which varies greatly across and within product categories. of shelving and draw upon consumer-specific success measures (i.e., data provided by means of eye tracking). Of course, there is another stream of the literature that emphasizes the retailer's perspective, concentrating on data such as sales, inventory, and category management, but this is beyond the scope of this study. Thus, this paper intends to contribute to consumer behaviour literature on retailing and shelf perception by providing further insights into this highly relevant topic.

The next section provides a brief overview of the relevant literature and develops two research questions. Section Method reports on the design of two laboratory and two field studies; a stationary eye tracker collects data for Lab Study I, and a mobile eye tracker is used in the other studies. Section Result presents the empirical findings achieved, and the last section concludes this paper by providing a summary of the contribution, limitations, and directions for future research.

\section{Theoretical Background and Research Questions}

In retailing, it is a matter of common knowledge that large assortments of products enable consumers to take into consideration potential benefits. Due to the essential heterogeneity across individual preferences, offering a wide range of products to consumers is preferred; thus, large assortments are utilized to target consumers with various tastes and circumstances (Mantrala et al., 2009). Today, time is money, and people have less of it to spend on shopping, so large assortments entail a shorter shopping time and enable customers to compare all the products more easily and directly (Hutchinson, 2005). However, large assortments can also lead to 'too many choices' and in turn, consumers may perceive them negatively, thereby creating dissatisfaction (Mantrala et al., 2009). Generally speaking, efficient space allocation has an impact on perceptibility, demand, profitability of certain goods and diverse costs (Zufryden, 1986).

\section{Attention, Perception, Behaviour}

A plethora of drivers is relevant for consumer perceptions on retail shelves (Chandon, Hutchinson \& Young, 2002). This study, however, follows the reasoning of Chandon et al. (2009), and focuses on attention-based factors (i.e., shelf position and number of facings). These factors aim to catch shoppers' in-store visual attention and to provide a "visual lift" for the merchandise presented in today's cluttered retail environments. Milosavljevic and Cerf (2008, p. 387) state that "attention serves as a processing bottleneck" because humans can never focus on everything that is presented and, therefore, most of the 
information - in particular, in low involvement situations like grocery shopping - remains unprocessed.

The literature distinguishes between two types of attention: bottom-up versus top-down. Bottom-up attention is rooted in evolutionary development and works both "automatically and unconsciously" (Berger, Wagner \& Schwand, 2012, p. 412). Bottom-up attention is generally considered to be active primarily at the beginning of a new task. Top-down attention operates goal-directed, depending on the task at hand. In the context of a supermarket, a consumer adhering to a shopping list will skip many shelves because she/he knows that the needed products will not be found there. Kroeber-Riel and Gröppel-Klein (2019) classify this as selective attention.

Having caught (visual) attention, some information might be selected and further cognitively processed; i.e., after their sensation perception recognizes, organizes, and makes sense of these stimuli. During this process, humans might (visually) examine these stimuli more thoroughly. Again, deeper selection processes will discard unnecessary information, but they might also induce behavioural consequences (i.e., for the given context, whether or not the product perceived should be included in the consideration set for purchases) (van Nierop et al., 2010, p. 63). Choosing one of the products in the consideration set, in turn, serves as a proxy for actual purchase (Chandon et al., 2009).

\section{Shelf Positioning of Products}

According to retail theory, merchandise presentation is classified into two basic types: 'on-shelf merchandising' and 'visual merchandising' (Dunne, Lusch \& Carver, 2014; Newman \& Cullen, 2002). The former refers to the products displayed on supermarket shelves, racks or counters throughout a store in order to boost sales and profits, while the latter focuses strongly on the visual merchandise that surround these such as the way the store is decorated to produce an overall feeling or atmosphere that facilitates purchases. In particular, shelving within 'on-shelf merchandising' is the main focus in this research. Indeed, the way retailers arrange the shelf displays sends a message about the store image, and in turn, affects buying behaviour at POP (Newman \& Cullen, 2002).

Campo and Gijsbrechts (2005) identify several key issues for research in the area of category management, in particular shelf layout (i.e., the vertical and horizontal position of products on the shelves). Valenzuela et al. (2013) discover that, at least to some extent, customers have certain expectations about shelf positioning: they anticipate products of high quality to be located on higher levels, but cheaper products (and heavy items) on lower levels; popular (and store) brands would be placed in the centre of the shelf ${ }^{2}$. However, in practice, these expectations materialize to only a limited extent.

It is common practice to distinguish between four vertical shelf zones (cf. Figure 3). The top level (also called stretch level, approximately above $6 \mathrm{ft}$.) is regarded as less valuable and even omitted in spacious stores. According to Dréze et al. (1994), eye level (4-5 ft. $\left.{ }^{3}\right)$ receives the most attention (cf. the adage "eye level is buy level"). Touch level (3-4 ft.) is located approximately at the shoppers' chest to waist height. Sigurdsson et al. (2009) found positive effects for products located on middle shelves (eye and touch level). The need to bend down to take something located at the bottom level (below $3 \mathrm{ft}$.) is presumed to have detrimental consequences on shoppers' demand.

Feria (2008, p. 1192), a psychologist, states that a centre bias is "a pervasive phenomenon in visual perception", which should also be valid for shelf spacing. Given this dominance, however, it is still interesting whether differences emerge for horizontal locations (i.e., left or right from the centre). Hansen et al. (2010, p. 95) argue that there is an advantage for products on the left since people tend to "...read shelves from left to right". The fact that the left visual field is initially processed in the right hemisphere of the brain and, thus, allows for a more holistic view (Janiszewski, 1990) supports the benefit of the left side. The superiority of the centre and the left-hand side of the shelf holds if the shopper stands directly in front of the shelf. A lot, however, seems to depend on which direction customers approach the shelf. Gröppel-Klein and Bartmann (2009) conducted empirical studies in two discount grocery stores with an identical assortment and identical prices, one guiding customers in a clockwise direction and the other in a counter-clockwise direction. These authors report a significant influence of walking direction on success measures (in particular, the formation of accurate mental maps). To date, research dealing with the interaction of walking direction and shelf perception has received little attention.

\section{The Number of Shelf Facings}

Refers to a measure of products exposed to subjects (Folwell \& Moberg, 1993). Consumers' attention tends to be caught more when the number of facings for the goods is

2 Retailers frequently use software for shelving and a common ruleof-thumb bases shelving decisions on respective market shares or profit margins; money-spinners are placed in the centre of the shelf, which then matches with the customers' expectations.

3 This numerical specification is an approximation only. In fact, the eye level of a person depends on her/his distance from the shelf and her/his body height. 
higher; thus, sales and impulse shopping can be stimulated by increasing the number of facings of the objects. In general, the greater the number of shelf facings of a stock keeping unit (SKU), the greater the probability of shoppers paying attention to it; and as a result, more purchases are made (Chandon et al., 2009; Mantrala et al., 2009; Oppewal \& Koelemeijer, 2005; Wedel \& Pieters, 2006). In terms of assortment evaluations, individuals pay more attention to large assortment sizes of available and favourite products (Amine \& Cadenat, 2003).

\section{Research Gap}

Extending on Kastner's (2019) literature review Appendix A reports on shelf-related research: 43 papers are listed in a chronological order with corresponding research objectives, empirical aspects and key findings. This facilitates detecting research progress over time, starting from the analysis of rather basic relationships between shelf assortment and sales, to more detailed investigations of shelf assortment on buyers' choices, and finally quite fine-tuned explorations of shelf assortment on behavioural aspects like consumers' attention and perception ${ }^{4}$. For convenience, Table 1 provides a summary of these papers, and distinguishes between the design of the empirical studies, type of data collected, investigated marketing stimuli, and research objectives. About $44 \%$ of the studies collected relevant sales or survey data (second column of Table 1), the other 56\% more recent studies employed eye tracking or video equipment.

Overall, empirical evidence, as reported in the literature, is inconsistent, especially with respect to the impact of shelf positions and the number of shelf facings. This might be due to different research objectives (retailer versus consumer perspective), different data sources, or different product categories analysed. Also, the research settings varied (e.g., sales and survey data were collected in the field, while eye tracking data was collected in the lab). Therefore, we decided to take a closer look at the impact of shelf positioning and the number of facings from a shopper perspective and pose the following research questions:

RQ1: What are the effects of the horizontal and vertical shelf positions on generated attention, perception, and purchase intention when accounting for walking direction and product category?

RQ2: What are the effects of the number of facings on generated attention, perception, and purchase intention when accounting for product category?

Some authors assign this kind of research to neuromarketing.
Figure 1 graphically displays the conceptual research model. The centre box represents the success variables analysed (predominantly measured by means of eye tracking). The left and right parts of Figure 1 denote RQ1 and RQ2 and the analysed triggers on the success variables. The four successive rectangles indicate that we conducted four empirical studies.

\section{Method}

\section{Design of the Studies}

The design of the studies followed the conceptual research model represented in Figure 1; we applied 3 $\times 2$ mixed experimental designs. The first within-subjects factor referred to is the product category. Somewhat replicating the study of Chandon et al. (2009), we first

Table 1. Summary of Shelf-related Research Papers

\begin{tabular}{|c|c|c|}
\hline \multirow{2}{*}{ Method $^{(1)}$} & \multicolumn{2}{|c|}{ Using eye tracking } \\
\hline & no & yes \\
\hline Field experiment or field study & 7 & 9 \\
\hline Laboratory experiment & 9 & 15 \\
\hline Observation & 6 & 1 \\
\hline \multicolumn{3}{|l|}{ Type of data collected ${ }^{(1)}$} \\
\hline Interview/questionnaire & 8 & 9 \\
\hline Items bought & 1 & 1 \\
\hline Sales data & 9 & 0 \\
\hline Mobile eye tracking & 0 & 6 \\
\hline Stationary eye tracking & 0 & 15 \\
\hline Video camera & 1 & 5 \\
\hline \multicolumn{3}{|l|}{ Investigated marketing stimuli ${ }^{(1)}$} \\
\hline Brand & 4 & 5 \\
\hline Product & 8 & 8 \\
\hline Shelf design & 2 & 8 \\
\hline Shelf facings & 3 & 1 \\
\hline Shelf position & 8 & 9 \\
\hline Shelf space & 4 & 1 \\
\hline Shopping time & 0 & 1 \\
\hline \multicolumn{3}{|l|}{ Research objectives ${ }^{(1)}$} \\
\hline (Visual) Attention \& perception & 3 & 17 \\
\hline Choice & 3 & 11 \\
\hline Orientation behaviour & 2 & 1 \\
\hline $\begin{array}{l}\text { Relationships between shelf factors and consumer } \\
\text { behaviour }\end{array}$ & 2 & 10 \\
\hline Relationships between shelf factors and sales & 9 & 2 \\
\hline Total number of papers included & 19 & 24 \\
\hline
\end{tabular}


decided to investigate grocery retailing because shelving is an important aspect for supermarkets. To allow for neat spacing, we searched for product categories with fairly similar shapes and sizes. Moreover, respondents should be familiar with the packaging so that they could easily recognize them. Finally, there should be a sufficient variety of different brands or flavours available to replenish a whole shelf ${ }^{5}$. Therefore, boxed tea, cereals, and crisps were chosen for these studies.

The second between-subjects factor refers to the walking direction (respondents were randomly assigned to either approach a shelf from the left or the right-hand side $)^{6}$. Subjects were asked to carry out a shopping task for all three product categories and to put one item in the shopping basket.

\section{Experimental Stimuli}

A preliminary study designed and tested the planograms used here (Zimprich, 2013). A planogram characterizes a graphic schema of a shelf layout relating to the exact location of the merchandise and the number of shelf facings per SKU (Dunne, Lusch \& Carver, 2014). Figure 3 presents the realization of the planogram for boxed tea. Given the fixed size of a typical retail shelf, the number of SKUs to be displayed depends on the size of the

5 For this reason, we abstained from choosing the same product categories as Chandon et al. (2009); i.e., soap and pain reliever.

6 As an example, we refer to Figure 2. Respondents either started with the shelf located in the background (i.e., the crisps shelf) and proceeded clockwise, or started with the cereals shelf and proceeded counter-clockwise. packages. Accounting for this constraint, we attempted to vary the number of facings across SKUs when designing planograms. In addition, multiple facings of the same SKU were placed next to each other on the same shelf board (or in some cases, on adjacent vertical shelf boards). Except for minor modifications, the planograms for each product category are identical across all studies.

\section{Planogram for Boxed Tea}

The size of the packaging for tea allowed for eight shelf boards (two packages could be stacked) and six packages per board; thus, in sum, a total of 96 tea packages were displayed (cf. Figure 3). Given that the cooperating supermarkets offered 24 different SKUs of boxed tea, the number of facings could vary $(2,4,6$, or 8$)$. According to van der Lans et al. (2008), similar products should be arranged in vertical blocks and, therefore, the tea planogram displayed similar flavours of tea in horizontal positions (e.g., fruit tea on the left side, see Appendix B for details). Respecting these constraints, positions for SKUs were otherwise assigned randomly.

\section{Planogram for Cereals}

The physical size of the shelf and the product packages resulted in 25 slots overall (i.e., five shelf boards and five packages per board). This allowed for variations between one, two or three facings allocated to 12 different types of cereals of the same brand. Apart from that, arrangement and final selection resembled the approach for boxed tea.

Figure 1. Conceptual Research Model




Figure 2. Shelf Arrangement in Field Study I

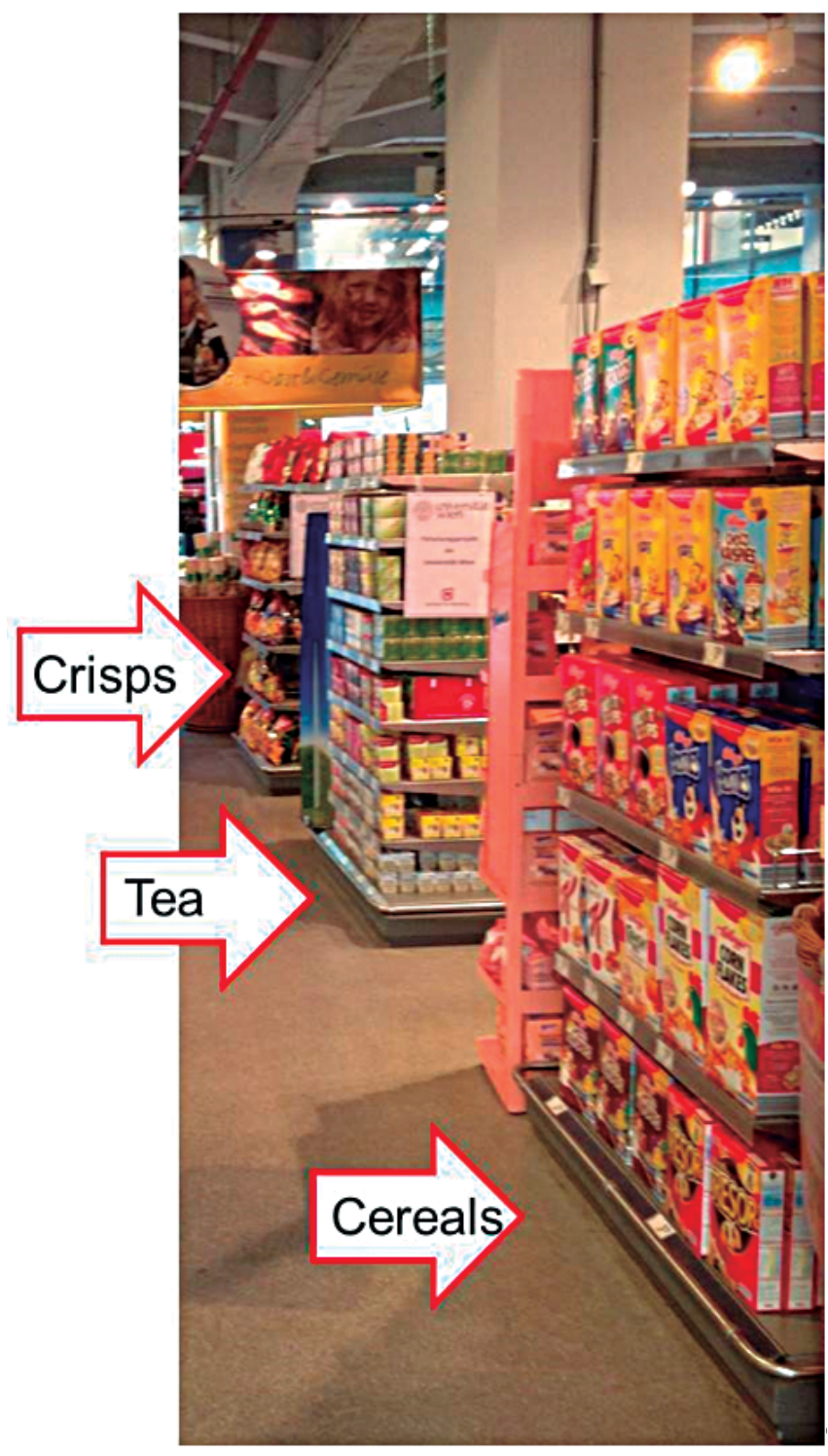

\section{Planogram for crisps}

There were six shelf boards and six packages per board in this case, and the six available brands fitted nicely into this space (i.e., random assignment of each brand to a certain board). The flavour of crisps (i.e., salty versus peppered) was considered an important attribute that induced horizontal arrangement (either left or right side). The number of facings (i.e., three) was held constant for all 12 SKUs ${ }^{7}$.

\section{Measurement}

As a special feature, this research used an observational method (eye tracking) for measuring most of the vari-

7 Further details on the design of the planograms for all three product categories are available upon request from the corresponding author.
Figure 3. Tea Shelf Used in Field Study I (Dashed White Rectangles Mark AOIs)

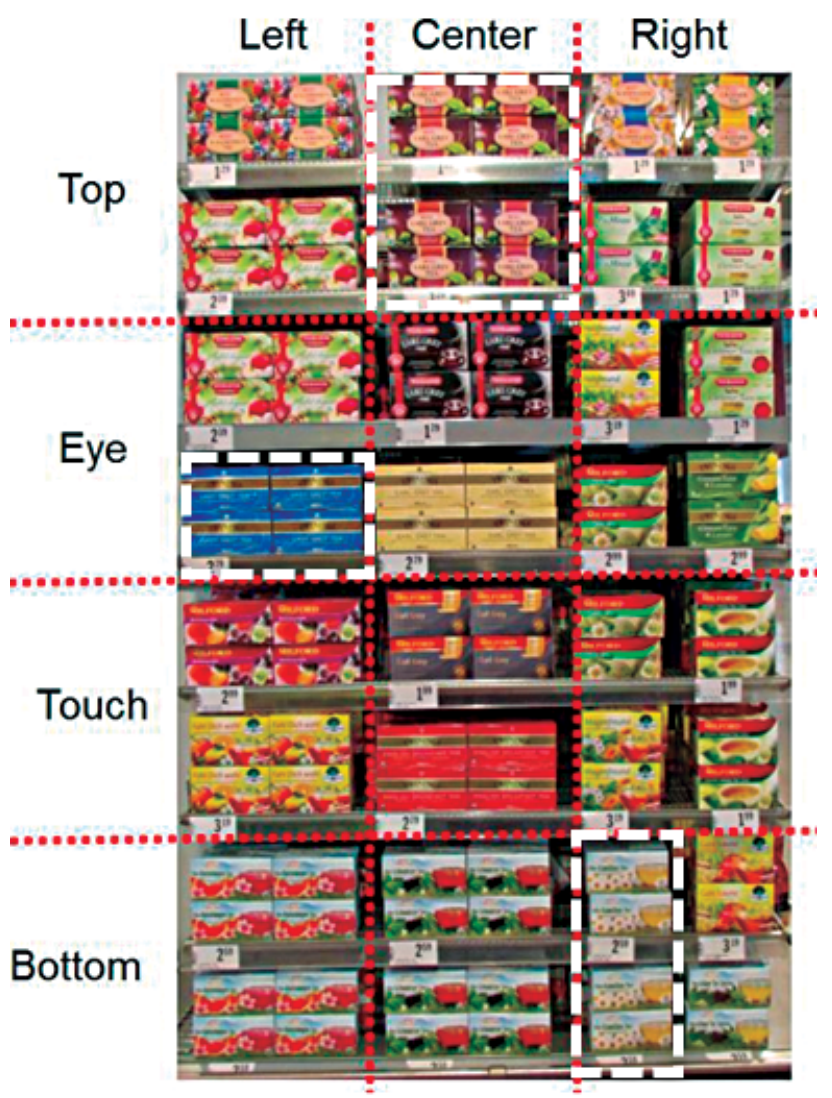

ables of interest. As outlined in As outlined in previous section, we distinguished between attention, perception, and behaviour, and determined these variables with respect to areas of interest (AOIs). For the present investigation, AOIs were defined such that they comprised the same SKUs for all product categories. In Figure 3, areas surrounded by dashed white rectangles represent examples for AOIs for three different SKUs with four or eight facings. Eye tracking recorded whether, and if so, for how long and in which succession, a participant gazed at a particular AOI.

Similar to Chandon et al. (2009), the duration of the first fixation measured attention for an AOI (in milliseconds, ms). Perception, i.e., further cognitive processing of information gazed at before, is quantified by (i) number of fixations within an AOI, and (ii) dwell time, the duration of all fixations and saccades within an AOI (in ms). This implied that the first term dealt with the question of how often and the second term focused on how long a participant looked at a specific AOI (SMI, 2014). The shopping task instructions asked subjects to visit the three shelves and to put the product of each product category into the shopping basket, which they intend to purchase. This allowed us to approximate purchase intention. 
For subsequent analysis, these variables accumulated at an individual level were aggregated over the experimental groups (i.e., subjects exposed to a certain shelf), resulting in 'average duration of the first fixation for an AOI', 'average number of fixations within an AOI', 'average dwell time within an AOI', and 'average purchase intention (for an SKU which resembles an $\mathrm{AOI}^{8}$ )'.

These different types of measurement require synchronized analyses. For attention and perception (based on eye movements), please note that our research questions refer to shelf positions or walking direction in general, but not to consumer specific patterns. Therefore, we feel that aggregating individual level data is justified. Potential differences should even out because of sufficient sample sizes. As a further and more important substantiation, respondents were looking at shelves, which were definitively unknown to them (because all three shelves had been designed just for our experiments). In this case, subjects' characteristics, like familiarity with the product category, did not matter ${ }^{9}$ and will not be accounted for subsequently. For purchase intention (based on products put in shopping baskets), however, product familiarity might have played a role. Therefore, when analysing purchase intention product familiarity will be considered.

\section{Different Store Environment Settings}

Safeguarding against isolated findings from a single study that might be subject to the specific environmental condition, a series of four different studies were conducted. We started with Lab Study I, which closely followed the design of Chandon et al. (2009). Respondents were sitting in front of a computer screen and were exposed to the experimental stimuli described previously ${ }^{10}$. A stationary eye tracking device recorded their eye movements. Adding external validity, but still controlling for external influences, Lab Study II assembled three supermarket shelves within a laboratory. These shelves were filled with boxed tea, cereals, and crisps, as described above. Access to the shelves could be modified, in order

8 At the individual level, purchase intention is a binary variable, at the aggregate level it is interpreted as the percentage of consumers who would buy this SKU.

9 The questionnaire asked for product familiarity, demographics and some other characteristics. In separate analyses, we did not identify striking differences with respect to these variables and reasons of practicability did not warrant the inclusion of these data in our models (1) or (2).

10 There are two exceptions for Lab Study I: First, there was only one group because walking direction could not be manipulated within this setting. Second, rather than putting products into the shopping basket, respondents communicated purchase intention verbally. to manipulate a clockwise or counter-clockwise walking direction. Participants wearing a mobile eye tracking device received a shopping basket, were asked to complete a shopping task, and were instructed from which side to enter the simulated aisle. The design of the Field Studies I and II was identical to Lab Study II, but these were conducted in real shopping environments (i.e., one store of two different grocery chains each $\left.{ }^{11}\right)$. Data collection for the field studies took place on weekdays during two subsequent weeks, separately for each study.

In none of the four studies subjects received monetary compensation for participation. However, we offered goodies or product vouchers as an incentive. For the field studies, some shoppers volunteered to participate out of curiosity (testing the eye tracker).

The stationary eye tracker allowed us to specify AOIs a priori, and variables of interest were calculated using computer software. The mobile eye tracker did not offer this feature, and, therefore, AOIs had to be coded manually. This was quite a laborious task because, on average, subjects needed between 11 and 32 seconds to complete the shopping task of one product category (which required about 45 to 90 minutes per shelf and respondent for coding).

\section{Sample Compositions}

Participants of all studies were blind to the research purpose, but were debriefed at the end of their task. The lab was located within the premises of a university in a European capital and, therefore, samples were mainly made up of academic employees and students. The shops were located in two different malls in the same city, and participants were recruited outside the supermarkets, i.e., they qualified for the studies by being typical shoppers. At the beginning of all studies, each subject had to individually undergo a calibration process in order to be able to participate in the experiment, regardless of whether we were using stationary or mobile eye tracking. The calibration process is fundamental for high quality data collection. The data quality (i.e. accuracy and precision of an eye tracker) was checked for all studies. In doing so, we had to eliminate much of the eye tracking data due to extremely bad data quality or data loss. Data cleansing resulted in the sample compositions (with respect to sizes and demographics), as described in Table 2.

On average, the time required for executing the shopping task was somewhat shorter within the more familiar

11 Product assortment varied between competing supermarkets. This required minor adjustments of the planograms for Field Study II in order to present only products, which are available in this particular store. 
environment of a store (rather than a lab), but quite similar otherwise (cf. middle part of Table 2). Given the greater variety on the shelf for boxed tea, it seems plausible that a longer duration was needed for the shopping task. The lower part of Table 2 presents the means of our success variables for each study. Patterns are similar; since there are more AOIs for tea, an "average tea AOI" is smaller than an "average cereal or crisp AOI" which results in somewhat longer first fixation durations and dwell times for tea required to grasp the relevant information. Higher purchase intentions in Lab Study I might be due to a testing effect.

\section{Results}

\section{Data Analysis}

Because of its widespread use in academia and practice, we chose the SCAN*PRO model (Wittink et al., 1988) for data analysis. Below, we describe how we adopted SCAN*PRO to fit the current application.

For each study $l$ ( $l=$ Lab Study I, Lab Study II, Field Study I, Field Study II) data were collected with sample size $n_{l}\left(n_{l}=47,40,19,38\right)$ (cf. Table 2$)$ and the following steps were carried out ${ }^{12}$ :

A) Preparation of stimuli, i.e., planograms (shelf arrangement) for each product category $s,(s=$ tea, cereals, crisps), $C_{s} \in\{0,1\}$, dummy variables reflecting product categories and determination of

- the number $I_{s}$ of SKUs $i$ presented in the shelf, $\left(I_{s}=24,12,12\right)(\mathrm{cf}$. Method $)$;

- the number of facings $F_{i s}$ per SKU $i, F_{i s} \in\{1, \ldots, 8\}$;

- the horizontal position $H_{i k s}$ of the SKU, $(k=$ left, centre, right) (cf. Figure 3), $H_{i k s} \in\{0,1\}$, dummy variables reflecting the horizontal position of SKU $i$;

- the vertical position $V_{i j s}$ of the SKU, $(j=$ top level, eye level, touch level, bottom level) (cf. Figure 3), $V_{i j s} \in\{0,1\}$, dummy variables reflecting the vertical position of SKU $i$.

12 We refrain from adding a further index $l$ in the sequel to all parameters and variables for notational convenience.

Table 2. Sample Characteristics

\begin{tabular}{|c|c|c|c|c|c|c|}
\hline \multirow{2}{*}{\multicolumn{3}{|c|}{$n$}} & Lab Study I & Lab Study II & Field Study I & Field Study II \\
\hline & & & 47 & $40(21+19)^{(1)}$ & $19(11+8)^{(1)}$ & $38(19+19)^{(1)}$ \\
\hline \multicolumn{3}{|c|}{ Female (\%) } & 55 & 53 & 63 & 47 \\
\hline \multicolumn{3}{|c|}{ Mean age (age range) } & $25(16-65)$ & $26(16-55)$ & $30(18-54)$ & $29(14-68)$ \\
\hline \multirow{3}{*}{\multicolumn{2}{|c|}{$\begin{array}{c}\text { Time } \\
\text { required for } \\
\text { shopping task (s) }\end{array}$}} & Tea & 28 & 32 & 16 & 14 \\
\hline & & Cereals & 16 & 25 & 13 & 13 \\
\hline & & Crisps & 23 & 27 & 11 & 17 \\
\hline \multicolumn{3}{|c|}{ First fixation duration $(\mathrm{ms})^{(2)}$} & 173 & 103 & 72 & 56 \\
\hline \multirow{3}{*}{$\begin{array}{l}\mathbf{T} \\
\mathbf{e} \\
\mathbf{a}\end{array}$} & Number of fix & & 130 & 76 & 13 & 21 \\
\hline & Dwell time ( $\mathrm{n}$ & & 820 & 737 & 285 & 215 \\
\hline & Purchase inte & & 4 & 2 & 2 & 2 \\
\hline \multirow{4}{*}{$\begin{array}{l}\mathrm{C} \\
\mathrm{e} \\
\mathbf{r} \\
\mathrm{e} \\
\mathbf{a} \\
\mathbf{l} \\
\mathrm{s}\end{array}$} & First fixation $\mathrm{c}$ & $\mathrm{ns})^{(2)}$ & 144 & 88 & 83 & 65 \\
\hline & Number of fix & & 124 & 88 & 22 & 34 \\
\hline & Dwell time ( $\mathrm{n}$ & & 704 & 866 & 469 & 365 \\
\hline & Purchase inte & & 6 & 3 & 3 & 3 \\
\hline c & First fixation $\mathrm{c}$ & $\mathrm{ns})^{(2)}$ & 112 & 82 & 47 & 31 \\
\hline $\begin{array}{l}\mathbf{r} \\
\mathbf{i}\end{array}$ & Number of fix & & 130 & 49 & 11 & 16 \\
\hline $\begin{array}{l}\mathbf{s} \\
\mathbf{p}\end{array}$ & Dwell time ( & & 787 & 409 & 231 & 216 \\
\hline s & Purchase inte & & 4 & 1 & 2 & 3 \\
\hline
\end{tabular}

(1) First and second numbers in the parenthesis refer to subjects approaching clockwise and counter-clockwise, respectively.

(2) Average across all AOI (number of AOI for tea 24, for cereals and crisps 12). 
B) Subjects $c\left(c=1, \ldots, n_{l}\right)$ approached shelves from direction $m,(m=$ clockwise, counter-clockwise), $W_{m} \in\{0,1\}$, dummy variables reflecting walking direction.

C) Eye tracking observations for each $\mathrm{AOI}^{13}$ and four success variables $(d=$ duration of the first fixation, dwell time, number of fixations, purchase intention): $y_{\text {ims }}^{c d}$.

D) Data preparation: averaging success variables over subjects (per AOI): $y_{i m s}^{d}=\sum_{c=1}^{n_{l}} m t c h_{i s} \cdot y_{i m s}^{c d}$ $\left./ n_{l} \quad \forall i, m, s, d \quad y_{i m s}^{d}>0\right\rfloor m t c h_{i s}:$ matching coefficient between AOI and shelf position (cf. Appendix $B$ for details).

E) Estimation of SCAN*PRO models:

$$
\begin{gathered}
\mathrm{RQ} 1: y_{i m s}^{. d}=\alpha_{0}^{\prime} \cdot \prod_{j} \beta_{j}^{V_{i j s}} \cdot \prod_{k} \gamma_{k}^{H_{i k s}} \cdot \prod_{m} \delta_{m}^{W_{m}} \cdot \prod_{s} \lambda_{s}^{C_{s}} \cdot e^{u_{i m s}} \\
\mathrm{RQ} 2: y_{i m s}^{. d}=\alpha_{0}^{\prime \prime} \cdot F_{i s}^{\alpha_{1}} \cdot \prod_{s} \lambda_{s}^{C_{s}} \cdot e^{u_{i m s}} \\
\alpha_{0}^{\prime}, \alpha_{0}^{\prime \prime}, \alpha_{1}, \beta_{j}, \gamma_{k}, \delta_{m}, \lambda_{s}: \text { response parameter } \\
u_{i m s} \text { error term }
\end{gathered}
$$

For reasons of identification, we set

$$
\beta_{\text {top level }}=\delta_{\text {counter-clockwise }}=\lambda_{\text {crisps }}=1
$$

With the exception of the product category-specific parameters $\lambda_{s}$, all other parameters are assumed constant across product categories; $\alpha_{1}$ is interpreted as facing elasticity; $\beta_{j}, \gamma_{k}, \delta_{m}, \lambda_{s}>0$ are called lift factors, i.e., the (percentage) up- or downward shift of the dependent variable if the exponent of the lift factor equals 1 (relative to the benchmark top level position, crisps product category, counter-clockwise walking direction) $)^{14}$.

13 The specification of our positional dummy variables defined a grid of twelve shelf positions for data analysis (cf. Figure 3). This granularity induced some loss of accuracy because, occasionally, these shelf positions and SKUs according to the planograms did not perfectly match (e.g., whereas SKU and the top centre position in Figure 3 coincide, this does not apply for the bottom right position). In such cases, we performed proportional matching of SKUs and shelf positions (as defined by the positional dummy variables) - see Appendix B for details. Consequently, some variance in terms of facings per shelf position emerged even for crisps (i.e., facings per SKU were constant for this product category).

14 We refrain from adding a further index $d$ to response parameters for notational convenience.
When considering purchase intention we added the term $\mathrm{fam}_{i s}^{\alpha_{2}}$, in (1) and (2) ( $\mathrm{fam}_{i s}$ consumers' familiarity with SKU $i$ in product category $s ; \alpha_{2}$ response elasticity) to account for brand knowledge.

\section{Comments On the Postulated Model}

The basic idea of (1) and (2) is similar to a fixed effect pooling model; i.e., we account for level effects of different product categories $\left(\lambda_{s}\right)$ but assume constant responses to shelf locations and walking direction: $\left(\beta_{j}, \gamma_{k}, \delta_{m}\right)$ do not depend on product category $s$. This implies, for example, that customers might need more time for perception of an AOI for tea than for cereals, but the effects of shelf positions and walking direction are similar across product categories. The latter view is consistent with common retail practice; shelf spacing considers size of product package, but does not explicitly consider product category nor walking direction.

Based on the intuition that a respective product has to be placed at some slot on the shelf anyway, the customer approaches from either side, and is looking for a certain product category, it becomes obvious that model (1) is not fully identified which requires (3). In a similar vein, the interpretation of lift factors $\beta_{j}, \gamma_{k}, \delta_{m}, \lambda_{s}$ as representing a proportional up- or downward shift points to the importance of the respective reference categories (in our case top-level for shelf position, counter clockwise for walking direction, and crisps for product category). The magnitude of these parameters can only be interpreted relatively rather than absolutely. Before estimation, (1) is log-transformed which also guarantees that the nonnegativity constraints will be satisfied.

Referring to extant literature (e.g., Dréze et al., 1994; Hansen et al., 2010) we expect $0<\alpha_{1}<1$ : increasing number of facings has a positive impact on success variables, but at a decreasing rate. Out of plausibility, the impact of product familiarity is supposed to be positive, i. e., $\alpha_{2}>0$.

\section{Interpretation of Results for RQ1}

In accordance with the conceptual model (Figure 1) and issues of identification, research questions 1 and 2 are analysed separately. Table 3 presents the results for estimating (1) by means of OLS ${ }^{15}$ (after log-transformation). We first note that model goodness-of-fit (in terms of $R^{2}$ ) and omnibus $F$-statistic are satisfactory for first fixation duration, number of fixations, and dwell time. The results for purchase intention in Lab Study II, as well as Field

15 The mixed experimental design resulted in evaluations of three shelves by each respondent. Aggregation of individual level observations to data per AOI precludes potential dependencies of the error term, which would necessitate GLS estimation. 
Studies I and II are statistically not reliable ${ }^{16}$, and the impact of product familiarity is not significant throughout. Many of the estimated lift-parameters are statistically significantly different from 1 , the benchmark ${ }^{17}$ (grey shaded in Table 3).

Overall, patterns are quite similar across studies and, in particular, for the two measures of perception (i.e., dwell time and number of fixations). Consistent with the literature, bottom level positions received weak evaluations; in particular, in terms of perception measures eye and touch level positions were superior. In accordance with Sorensen (2016), the importance of horizontal over vertical positions clearly manifests - with the exception of purchase intention for Field Studies I and II, all horizontal level parameters significantly exceed 1 . There is no definite answer about which of the three horizontal positions is preferable. In most of the shops operating in the country of investigation, the counter-clockwise walking direction is more common and, therefore, participants might have favoured this walking direction out of habit. Inconclusive results emerge for the product category. In most cases, however, multiplication of the estimated parameter for the constant times for the product category (e.g., for first fixation duration, Lab Study II: $64.32 \times(1.18$ $|1.05| 1)=76|68| 64)$ resembles patterns shown in the lower part of Table 2 (i.e., averages of dependent variables per product category; $103|88| 82$ ).

As an aside, model (1) allows simultaneous assessment of all 12 shelf positions by calculating $\hat{\beta}_{j} \cdot \hat{\gamma}_{k} \forall j, k$. Figure 4 illustrates these figures for all dependent variables and all studies. Being lift factors, the numbers in Figure 4 are relative with respect to the magnitude of the dependent variable considered and, therefore, are neither comparable across dependent variables nor across studies. To facilitate such a comparison, however, colour shading is applied, whereby dark blue represents the highest and light blue the lowest value ${ }^{18}$. Across all studies, consistencies exist to the degree that eye and touch level positions are preferred over top and bottom level positions. With the exception of Lab Study I (using a stationary eye tracker), eye level seems to perform best (which, of course, is consistent with common practice). For the two field studies, non-centre positions perform very well. We believe that this is a consequence of accounting for walking direction: shoppers entering an aisle have a greater

16 Some SKUs were not chosen at all which resulted in an aggregated purchase intention of zero in these cases. In turn, this might have caused detrimental effects for statistical parameter estimation.

17 In fact, $t$-Tests analysed whether, for instance, $\ln \left(\beta_{j}\right)$ is significantly different from zero.

18 The domain of each combination of success variables and studies (for instance, [1.36, 2.12] for first fixation duration, Lab Study I) is mapped into the colour domain, i.e., [low: light blue, high: dark blue]. chance of perceiving products that are near to them; the reader should keep in mind that literature claiming superiority of centre locations assumes customers to be positioned in front of the shelf.

\section{Interpretation of Results for RQ2}

The same estimation procedure as for (1) calibrates parameters of (2); they are presented in Table 4. Again, goodness-of-fit (in terms of $R^{2}$ ) and omnibus $F$-statistic are satisfactory (with the exception of purchase intention for Field Studies I and II). Estimates for facing elasticities are fairly stable across studies, but depend on the dependent variable considered. They are significantly different form zero (with the exception of purchase intention). Their magnitude is somewhat larger than the elasticities reported by Curhan (1972) - using sales data - or Chandon et al. (2009). Again, the effect found for familiarity is statistically not significantly different from zero. There is also some consistency with respect to the product category. Overall, lift factors for tea are smaller than 1 ; but those for cereals are larger than 1 . The number of slots amounts to 96, 25, 36 for boxed tea, cereals, and crisps, respectively (cf. Method), and there are 24, 12, and 12 AOIs. Since dependent variables refer to AOIs, it makes sense that (relative) success measures for boxed tea are smaller for cereals and larger than for crisps. Altogether, these results have face validity.

\section{Contribution, Limitations, and Further Research}

\section{Contribution}

We believe that this research contributes to the literature in three ways. First, we provide further evidence of the more pronounced importance of horizontal shelf positioning over the vertical arrangement. Whereas eye and touch level positions are indeed privileged, we provide empirical evidence that walking direction has a major impact on noticing merchandise and that the general wisdom of the superiority of centre locations does not hold for a dynamic environment; right or left from the centre might be better if a shopper approaches from the right or left, respectively. In addition, we corroborate the findings on facing elasticities smaller than 1 (i.e., diminishing returns for increasing the number of facings). Second, by conducting a series of studies, two of them in a lab and two in the field, this research scores on internal and external validity. It thus also followed the call for replication studies in this area. Mostly, our results are consistent across studies conducted in different environments. Third, eye tracking measured success variables, and this method is not restrained by subjectivity biases. Respondents 
Table 3 Results of RQ1 (Non-standardized Regression Parameters are Shown)

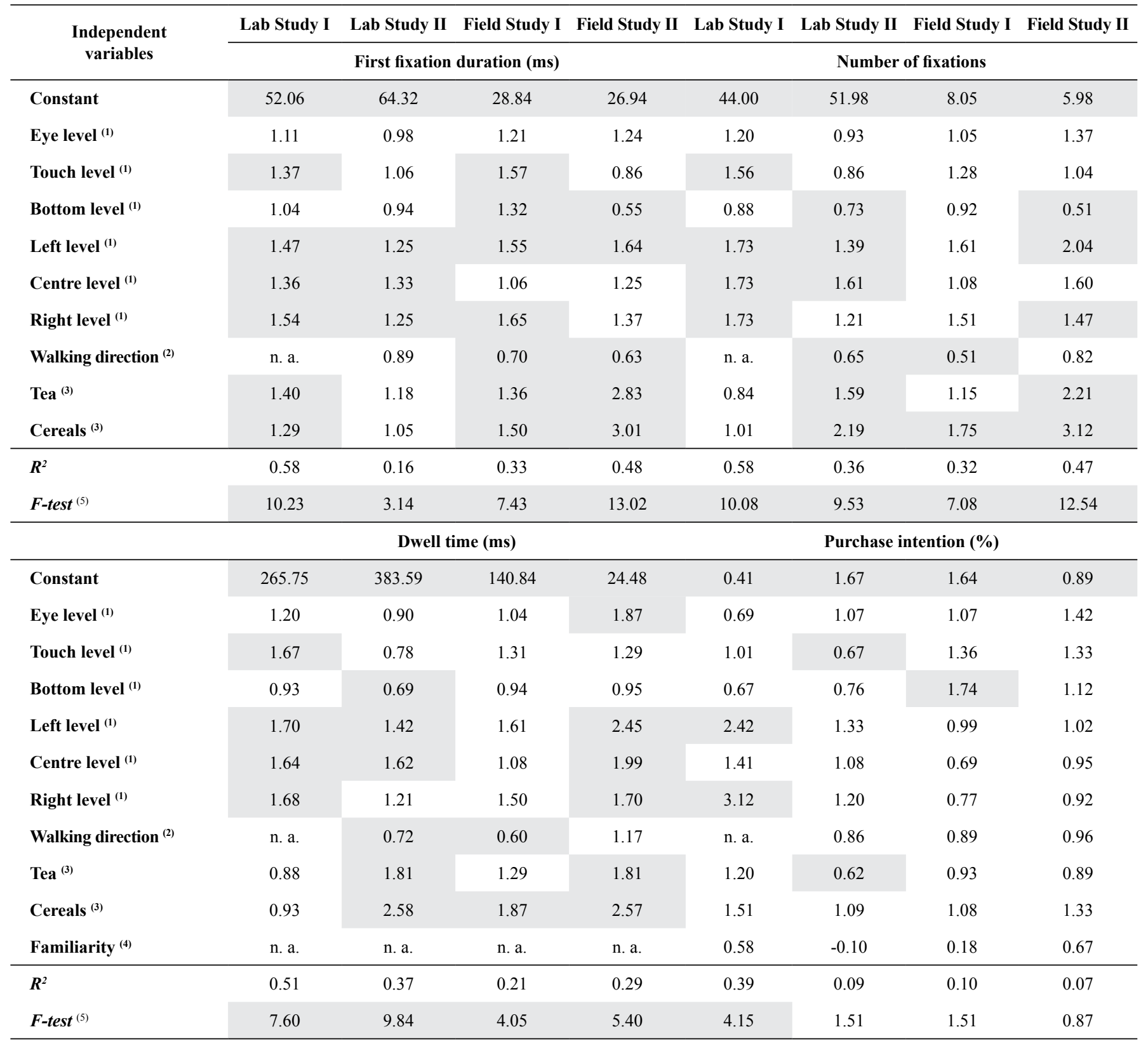

(1) relative to top level

(2) clockwise (relative to counter-clockwise), n. a.: not applicable for Lab Study I

(3) relative to crisps

${ }^{(4)}$ n. a.: not applicable for dwell time

${ }^{(5)}$ corresponding degrees of freedom depend on number of AOIs and number of estimated parameters

Entries shaded in grey highlight estimates significantly different from 1 (for constant, positional variables, walking direction, tea, cereals), from 0 (for familiarity) or significantly different from a $F$-distribution's critical value for a type I error of 0.05 .

Measurement of purchase intention by communication in Lab Study I and observation in other studies.

reported that they did not feel accommodated when wearing eye tracking glasses and did not indicate reactive behaviour. On the contrary, subjects were able to move their head and body freely, confirming external validity. Finally, we point to the interest of practitioners in this research. Retailers assessed our study to be highly rele- vant, allowed for data collection in their stores, and asked for information about our empirical evidence.

\section{Limitations}

Our research is limited in scope because it concentrates on shopping behaviour and, in particular, on attention, perception, and purchase intention. On the one hand, 
Figure 4. Relative Assessment of Shelf Positions

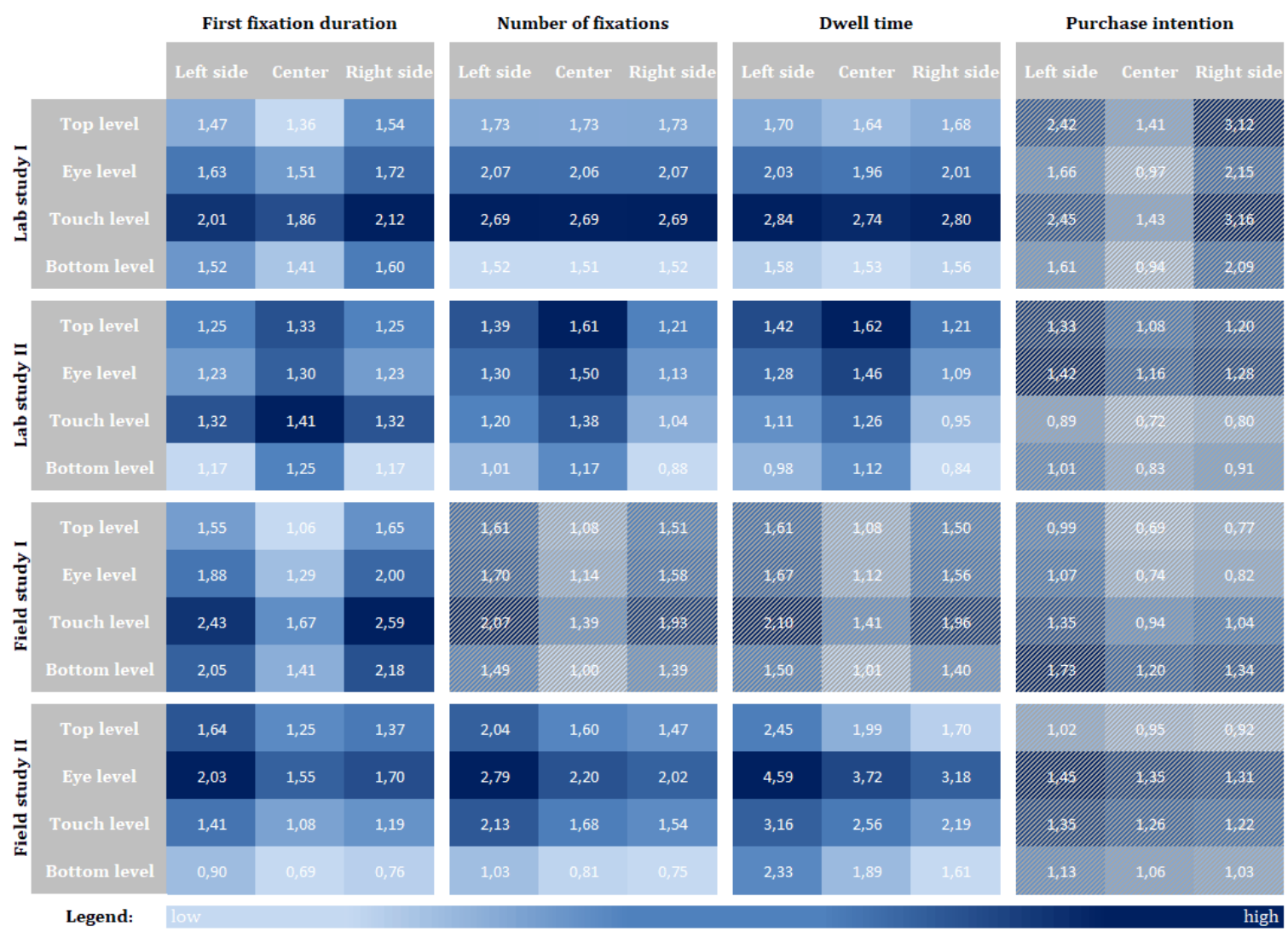

Note: Shaded areas indicate assessments, which are reported due to reasons of completeness; their statistical reliability is in doubt.

Table 4. Results of RQ2 (Non-standardized Regression Parameters are Shown)

\begin{tabular}{|c|c|c|c|c|c|c|c|c|}
\hline $\begin{array}{l}\text { Independent } \\
\text { variables }\end{array}$ & Lab Study I & Lab Study II & Field Study I & Field Study II & Lab Study I & Lab Study II & Field Study I & Field Study II \\
\hline Constant & 81.89 & 71.21 & 33.87 & 11.06 & 82.37 & 33.75 & 6.35 & 4.57 \\
\hline Number of facings & 0.70 & 0.52 & 0.58 & 0.70 & 0.94 & 0.71 & 0.65 & 0.81 \\
\hline Tea $^{(1)}$ & 0.87 & 0.75 & 0.91 & 2.46 & 0.46 & 0.88 & 0.75 & 1.81 \\
\hline \multirow[t]{2}{*}{$F$-test ${ }^{(3)}$} & 26.53 & 9.67 & 15.35 & 18.50 & 20.41 & 18.11 & 11.74 & 14.96 \\
\hline & \multicolumn{4}{|c|}{ Dwell time (ms) } & \multicolumn{4}{|c|}{ Purchase intention (\%) } \\
\hline Constant & 495.45 & 275.03 & 122.03 & 77.96 & 0.69 & 1.45 & 1.44 & 1.11 \\
\hline Number of facings & 0.94 & 0.72 & 0.62 & 0.88 & 1.43 & 0.41 & 0.45 & -.13 \\
\hline Familiarity ${ }^{(2)}$ & n. a. & n. a. & n. a. & n. a. & 0.54 & -0.30 & 0.13 & 0.59 \\
\hline$R^{2}$ & 0.43 & 0.30 & 0.16 & 0.17 & 0.24 & 0.05 & 0.05 & 0.03 \\
\hline$F$-test $t^{(3)}$ & 16.28 & 22.03 & 8.90 & 8.42 & 4.85 & 2.11 & 1.87 & 1.12 \\
\hline
\end{tabular}

(1) relative to crisps

(2) corresponding degrees of freedom depend on number of AOIs and number of estimated parameters

${ }^{(3)}$ n. a.: not applicable for dwell time

Entries shaded in grey highlight estimates significantly different from 1 (for constant, tea, cereals), from 0 (for number of facings) or significantly different from a $F$-distribution's critical value for a type I error of 0.05 . 
this assumes rather goal-directed behaviour and refrains from analysing pure search behaviour, which might be important for impulsive buying or more hedonic products. On the other hand, the success variables considered are effective at the beginning of a buying decision process, and their relevance might diminish when it comes to actual purchase. Indeed, the results for purchase intention are already quite weak. At the same time, we did not consider external influences (e.g., price labels, signage, illumination, store atmosphere) or consumer characteristics (e.g., height, which might have an impact on what is subjectively considered as eye level; left- or right-handedness, which might impact preferences for horizontal positions). The SCAN*PRO model is rather simple and does not account for saturation effects (of facings). Moreover, relationships between success variables might be more sophisticated (e.g., perception might mediate the influence of shelf positions on purchase intention).

Another limitation results from sampling: basically, convenience sampling was performed, in particular for the lab studies. The sample sizes are modest, but in accordance with common practice (cf. Appendix A, column "products/sample"). The cumbersome coding procedure for preparing data from mobile eye tracking prevented us from large-scale studies. In addition, some subjects did not qualify for eye tracking because they wore glasses, mascara, or hard contact lenses. In some cases, subjects were asked to remove earrings or cover colourful apparel with a scarf. We do not believe, however, that this resulted in a systematic selection bias.

\section{Further Research}

The limitations outlined above open multiple avenues for further research. In addition to these, we mention that the number of potential planograms increases combinatorically, but we only analysed one per product category (which were pretested in another research); given the same set-up, the effects of different planograms could be investigated. The research selected three product categories that appeared to be especially suitable. Nevertheless, other product categories (e.g., yogurt, shampoo, soap, pain reliever) are also appropriate. Two of the studies were conducted in the field, in supermarkets of considerable size (i.e., with an assortment of about 15,000 SKUs), essentially with a grid layout. Store size and store layout might affect shopping behaviour and, therefore, further research should consider other types of stores. Our studies analysed groceries. However, shelf display of products is common practice for many other retailing categories (e.g., clothes, hardware, drug-store products); further research in these industries is called for. Finally, our studies were conducted in a European cap- ital; the population was culturally diverse, but respondents predominantly had a central European cultural background. This might limit the transferability of the findings, e.g., to Arabian, Jewish or Chinese backgrounds, where shoppers are used to less spacious stores and different shopping patterns. Moreover, the reading habits of consumers may play an important role in the research of shelf perceptions as well. Thus, it would be interesting to replicate our study in such environments.

In conclusion, we hope that this research, not only provides significant findings, but also encourages academics and marketers to continue examining shelf perceptions.

\section{Acknowledgement}

The corresponding author thanks the University of Vienna for providing research fellowship; the Austrian Chamber of Commerce for the research award; and the Academy Anniversary Foundation of Vienna for financial support.

\section{References}

Amine, A., \& Cadenat, S. (2003). Efficient retailer assortment: A consumer choice evaluation perspective. International Journal of Retail \& Distribution Management, 31(10), 486-497.

Atalay, A. S., Bodur, H. O., \& Rasolofoarison, D. (2012). Shining in the centre: Central gaze cascade effect on product choice. Journal of Consumer Research, 39(4), 848-866.

Behe, B. K., Bae, M., Huddleston, P. T., \& Sage, L. (2015). The effect of involvement on visual attention and product choice. Journal of Retailing and Consumer Services, 24, 10-21.

Benjamapornkul, R., Rakthin, S., \& Punnakitikashem, P. (2016). The impact of visual merchandising management on customer attraction in retail stores. International Economic Review, 14(3), 693-709.

Berger, S., Wagner, U., \& Schwand, C. (2012). Assessing advertising effectiveness: The potential of goaldirected behaviour. Psychology \& Marketing, 29(6), 411-421.

Bialkova, S., Grunert, K. G., \& van Trijp, H. (2020). From desktop to supermarket shelf: Eye-tracking exploration on consumer attention and choice. Food Quality and Preference, 81, 103839.

Bogomolova, S., Oppewal, H., Cohen, J., \& Yao, J. (2020). How the layout of a unit price label affects eye-movements and product choice: An eye-tracking investigation. Journal of Business Research, 111, 102-116.

Broniarczyk, S. M., Hoyer, W. D., \& McAlister, L. (1998). Consumers' perceptions of the assortment offered in a grocery category: The impact of item reduction. Journal of Marketing Research, 35(2), 166-176. 
Burke, R. R., \& Leykin, A. (2014). Identifying the drivers of shopper attention, engagement, and purchase. In Shopper Marketing and the Role of In-Store Marketing. (Review of Marketing Research, Vol. 11). Emerald Group Publishing Limited, 147-187.

Campo, K., \& Gijsbrechts, E. (2005). Retail assortment, shelf and stock out management: Issues, interplay and future challenges. Applied Stochastic Models in Business and Industry, 21(4-5), 383-392.

Chandon, P., Hutchinson, J. W., Bradlow, E., \& Young, S. H. (2007). Measuring the value of point-of-purchase marketing with commercial eye-tracking. INSEAD Business School Research Paper.

Chandon, P., Hutchinson, J. W., Bradlow, E. T., \& Young, S. H. (2009). Does in-store marketing work? Effects of the number and position of shelf facings on brand attention and evaluation at the point of purchase. Journal of Marketing, 73(6), 1-17.

Chandon, P., Hutchinson, J. W., \& Young, S. H. (2002). Unseen is unsold: Assessing visual equity with commercial eye-tracking data. Internal Paper, INSEAD.

Chevalier, M. (1975). Increase in sales due to in-store display. Journal of Marketing Research, 12(4), 426-431.

Christenfeld, N. (1995). Choices from identical options. Psychological Science, 6(1), 50-55.

Clement, J., Kristensen, T., \& Grønhaug, K. (2013). Understanding consumers' in-store visual perception: The influence of package design features on visual attention. Journal of Retailing and Consumer Services, 20(2), 234-239.

Cox, K. K. (1964). The responsiveness of food sales to shelf space changes in supermarkets. Journal of Marketing Research, 1(2), 63-67.

Cox, K. K. (1970). The effect of shelf space upon sales of branded products. Journal of Marketing Research, $7(1), 55-58$.

Curhan, R. C. (1972). The relationship between shelf space and unit sales in supermarkets. Journal of Marketing Research, 9(4), 406-412.

Deng, X., Kahn, B. E., Unnava, H. R., \& Lee, H. (2016). A "wide" variety: Effects of horizontal versus vertical display on assortment processing, perceived variety, and choice. Journal of Marketing Research, 53(5), 682-698.

Dhar, S. K., Hoch, S. J., \& Kumar, N. (2001). Effective category management depends on the role of the category. Journal of Retailing, 77(2), 165-184.

Drexler, D. \& Souček, M. (2016). The influence of sweet positioning on shelves on consumer perception. Food Packaging and Shelf Life, 10, 34-45.

Dréze, X., Hoch, S. J., \& Purk, M. E. (1994). Shelf management and space elasticity. Journal of Retailing, 70(4), 301-326.
Dunne, P. M., Lusch, R. F., \& Carver, J. R. (2014). Retailing ( $8^{\text {th }}$ Ed.). South-Western, Cengage Learning.

Feria, C. S. (2008). The distribution of attention within objects in multiple-object scenes: Prioritization by spatial probabilities and a centre bias. Perception \& Psychophysics, 70(7), 1185-1196.

Ferreira, P., Han, Q., \& Costeira, J. P. (2018). The effect of product placement on shopping behaviour at the point of purchase: Evidence from randomized experiment using video tracking in a physical bookstore. Available at SSRN 3288604.

Folwell, R. J., \& Moberg, D. A. (1993). Factors in retail shelf management impacting wine sales. Agribusiness, 9(6), 595-603.

Frank, R. E., \& Massy, W. F. (1970). Shelf position and space effects on sales. Journal of Marketing Research, 7(1), 59-66.

Gidlöf, K., Anikin, A., Lingonblad, M., \& Wallin, A. (2017). Looking is buying. How visual attention and choice are affected by consumer preferences and properties of the supermarket shelf. Appetite, 116, 29-38.

Gidlöf, K., Wallin, A., Dewhurst, R., \& Holmqvist, K. (2013). Using eye tracking to trace a cognitive process: Gaze behaviour during decision making in a natural environment. Journal of Eye Movement Research, $6(1), 1-14$.

Gómez, M., \& Rubio, N. (2008). Shelf management of store brands: Analysis of manufacturers' perceptions. International Journal of Retail \& Distribution Management, 36(1), 50-70.

Gröppel-Klein, A., \& Bartmann, B. (2009). Turning bias and walking patterns: Consumers' orientation in a discount store. Marketing JRM, 1, 43-56.

Hansen, J. M., Raut, S., \& Swami, S. (2010). Retail shelf allocation: A comparative analysis of heuristic and meta-heuristic approaches. Journal of Retailing, 86(1), 94-105.

Hoch, S. J., Bradlow, E. T., \& Wansink, B. (1999). The variety of an assortment. Marketing Science, 18(4), 527-546.

Hutchinson, J. (2005). Is more choice always desirable? Evidence and arguments from leks, food selection, and environmental enrichment. Biological Reviews, 80(1), 73-92.

Janiszewski, C. (1990). The influence of non-attended material on the processing of advertising claims. Journal of Marketing Research, 27(3), 263-278.

Kahn, B. E., \& Wansink, B. (2004). The influence of assortment structure on perceived variety and consumption quantities. Journal of Consumer Research, 30(4), 519-533.

Kastner, J. (2019). Consumer perceptions of supermarket shelves: Using mobile and stationary eye trackers. Unpublished PhD dissertation, University of Vienna. 
Kroeber-Riel, W., \& Gröppel-Klein, A. (2019). Konsumentenverhalten. [Consumer Behaviour]. 11 ${ }^{\text {th }}$ Ed., Vahlen.

Liu, X., Krahnstoever, N., Yu, T., \& Tu, P. (2007). What are customers looking at? 2007 IEEE Conference on Advanced Video and Signal Based Surveillance, 405410.

Mantrala, M. K., Levy, M., Kahn, B. E., Fox, E. J., Gaidarev, P., Dankworth, B., \& Shah, D. (2009). Why is assortment planning so difficult for retailers? A framework and research agenda. Journal of Retailing, 85(1), 71-83.

Massara, F., Porcheddu, D., \& Melara, R. D. (2014). Asymmetric perception of sparse shelves in retail displays. Journal of Retailing, 90(3), 321-331.

Milosavljevic, M., \& Cerf, M. (2008). First attention then intention: Insights from computational neuroscience of vision. International Journal of Advertising, 27(3), 381-398.

Monteiro, P., Guerreiro, J., \& Loureiro, S. M. C. (2019). Understanding the role of visual attention on wines' purchase intention: An eye-tracking study. International Journal of Wine Business Research, 32(2), 161179.

Newman, A. J. \& Cullen, P. (2002). Retailing: Environment \& operations. South-Western, Cengage Learning, Hampshire.

Nordfält, J., Grewal, D., Roggeveen, A. L., \& Hill, K. M. (2014). Insights from in-store marketing experiments. In: Grewl, D., Roggeveen, A. L., \& Nordfält, J. (eds.), Review of Marketing Research: Shopper Marketing and the Role of In-Store Marketing, 11, Emerald Books.

Pärnamets, P., Johansson, P., Hall, L., Balkenius, C., Spivey, M. J., \& Richardson, D. C. (2015). Biasing moral decisions by exploiting the dynamics of eye gaze. Proceedings of the National Academy of Sciences, 112(13), 4170-4175.

Oppewal, H., \& Koelemeijer, K. (2005). More choice is better: Effects of assortment size and composition on assortment evaluation. International Journal of Research in Marketing, 22(1), 45-60.

Pieters, R., \& Warlop, L. (1999). Visual attention during brand choice: The impact of time pressure and task motivation. International Journal of Research in Marketing, 16(1), 1-16.

Russo, J. E., \& Leclerc, F. (1994). An eye-fixation analysis of choice processes for consumer nondurables. Journal of Consumer Research, 21(2), 274-290.

Schröder, H., Berghaus, N., \& Zimmermann, G. (2005). Das Blickverhalten der Kunden als Grundlage für die Warenplatzierung im Lebensmitteleinzelhandel. [The gaze behaviour of customers as the basis for the product placement in retailing], der Markt, 44(1), 31-43.
Sigurdsson, V., Saevarsson, H., \& Foxall, G. (2009). Brand placement and consumer choice: An in-store experiment. Journal of Applied Behaviour Analysis, 42(3), 741-745.

SMI (2014). Sensomotoric instruments (SMI). https:// www.facebook.com/smieyetracking/ (accessed August, $\left.24^{\text {th }}, 2020\right)$.

Sorensen, H. (2016). Inside the mind of the shopper: The science of retailing. FT Press.

Valenzuela, A., \& Raghubir, P. (2009a). Position-based beliefs: The centre-stage effect. Journal of Consumer Psychology, 19(2), 185-196.

Valenzuela, A., \& Raghubir, P. (2009b). Are top-bottom inferences conscious and left-right inferences automatic? Implications for shelf space positions. HEC Paris INSEAD Fontainebleau, 19, 185-196.

Valenzuela, A., \& Raghubir, P. (2015). Are consumers aware of top-bottom but not of left-right inferences? Implications for shelf space positions. Journal of Experimental Psychology: Applied, 21(3), 224-258.

Valenzuela, A., Raghubir, P., \& Mitakakis, C. (2013). Shelf space schemas: Myth or reality? Journal of Business Research, 66(7), 881-888.

van der Lans, R., Pieters, R., \& Wedel, M. (2008). Competitive brand salience. Marketing Science, 27(5), 922931.

van Nierop, E., Bronnenberg, B., Paap, R., Wedel, M., \& Franses, P. H. (2010). Retrieving unobserved consideration sets from household panel data. Journal of Marketing Research, 47(1), 63-74.

Wästlund, E., Shams, P., \& Otterbring, T. (2018). Unsold is unseen... or is it? Examining the role of peripheral vision in the consumer choice process using eye-tracking methodology. Appetite, 120(1), 49-56.

Wedel, M. \& Pieters, R. (2006). Eye tracking for visual marketing. Foundations and Trends in Marketing, 1(4), 231-320.

Wedel, M. \& Pieters, R. (Eds.). (2008). Visual marketing: From attention to action. Lawrence Erlbaum Associates.

Wittink, D. R., Addona, M. J., Hawkes, W. J., \& Porter, J. C. (1988). SCAN*PRO: The estimation, validation and use of promotional effects based on scanner data. Internal Paper, Cornell University.

Zimprich, M. (2013). Suchlogik am Regal im Einzelhandel. [Search logic on the supermarket shelves]. Unpublished Master thesis, University of Vienna.

Zufryden, F. S. (1986). A dynamic programming approach for product selection and super- market shelf-space allocation. Journal of the Operational Research Society, 37(4), 413-422. 


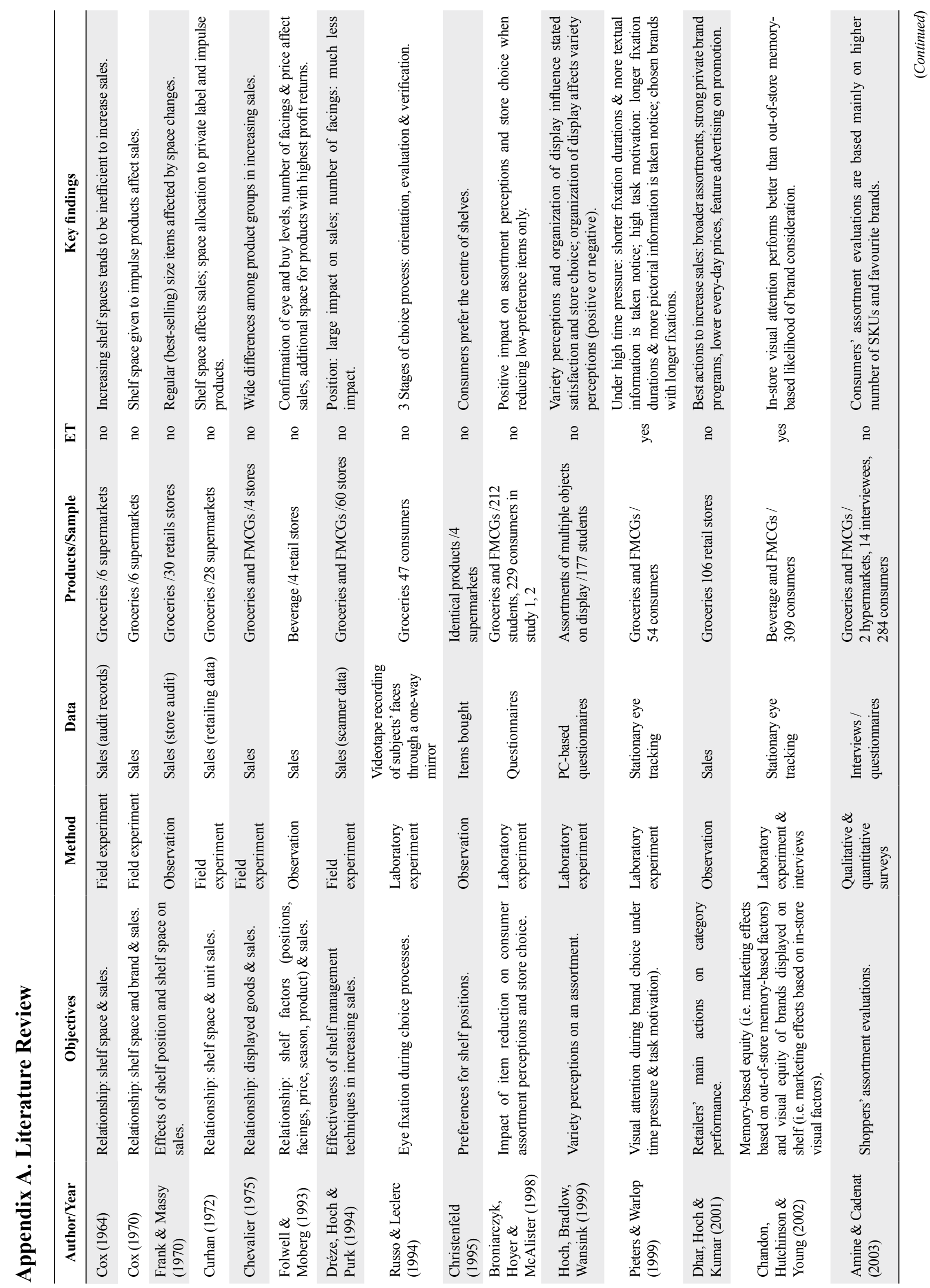




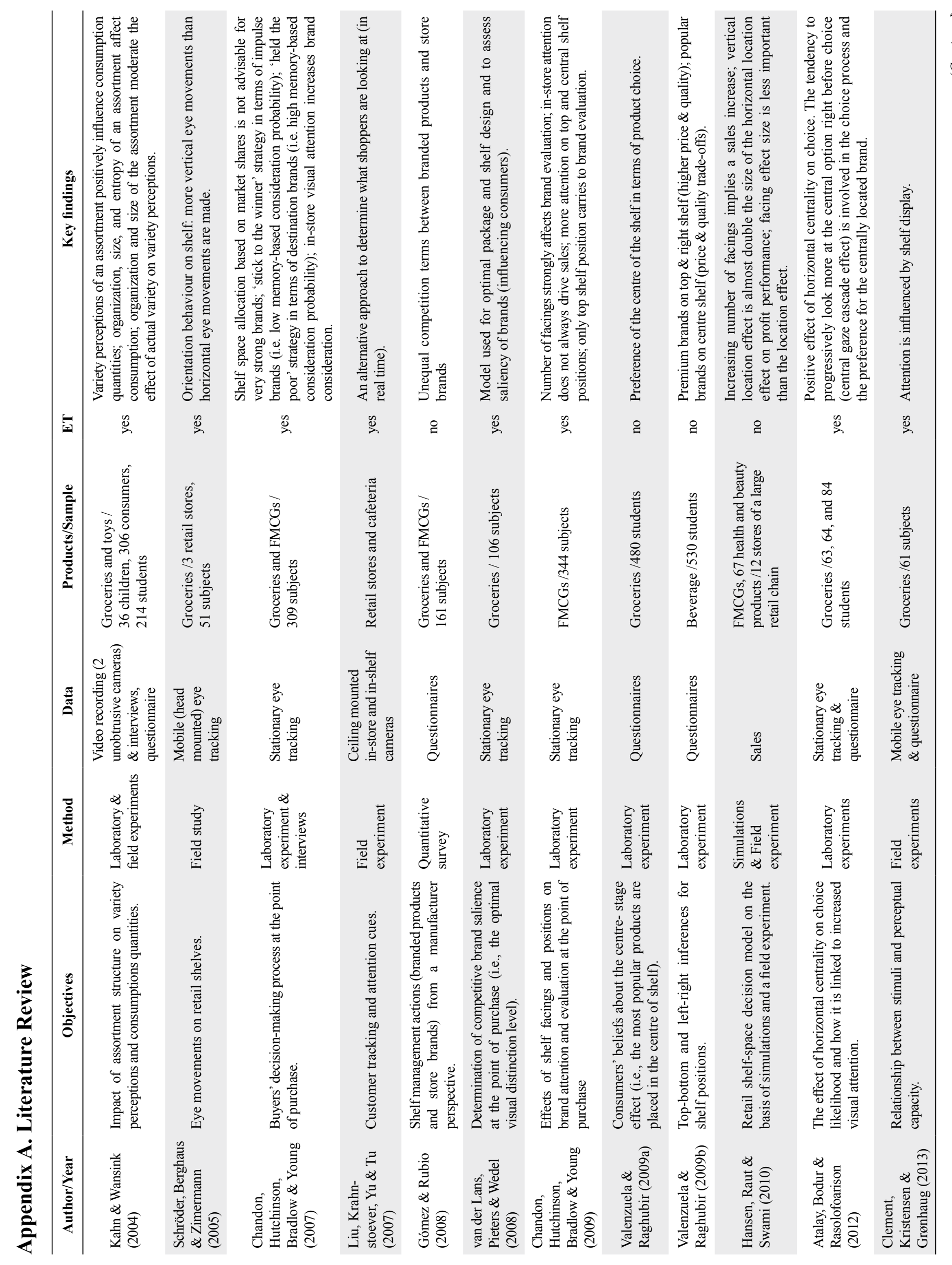




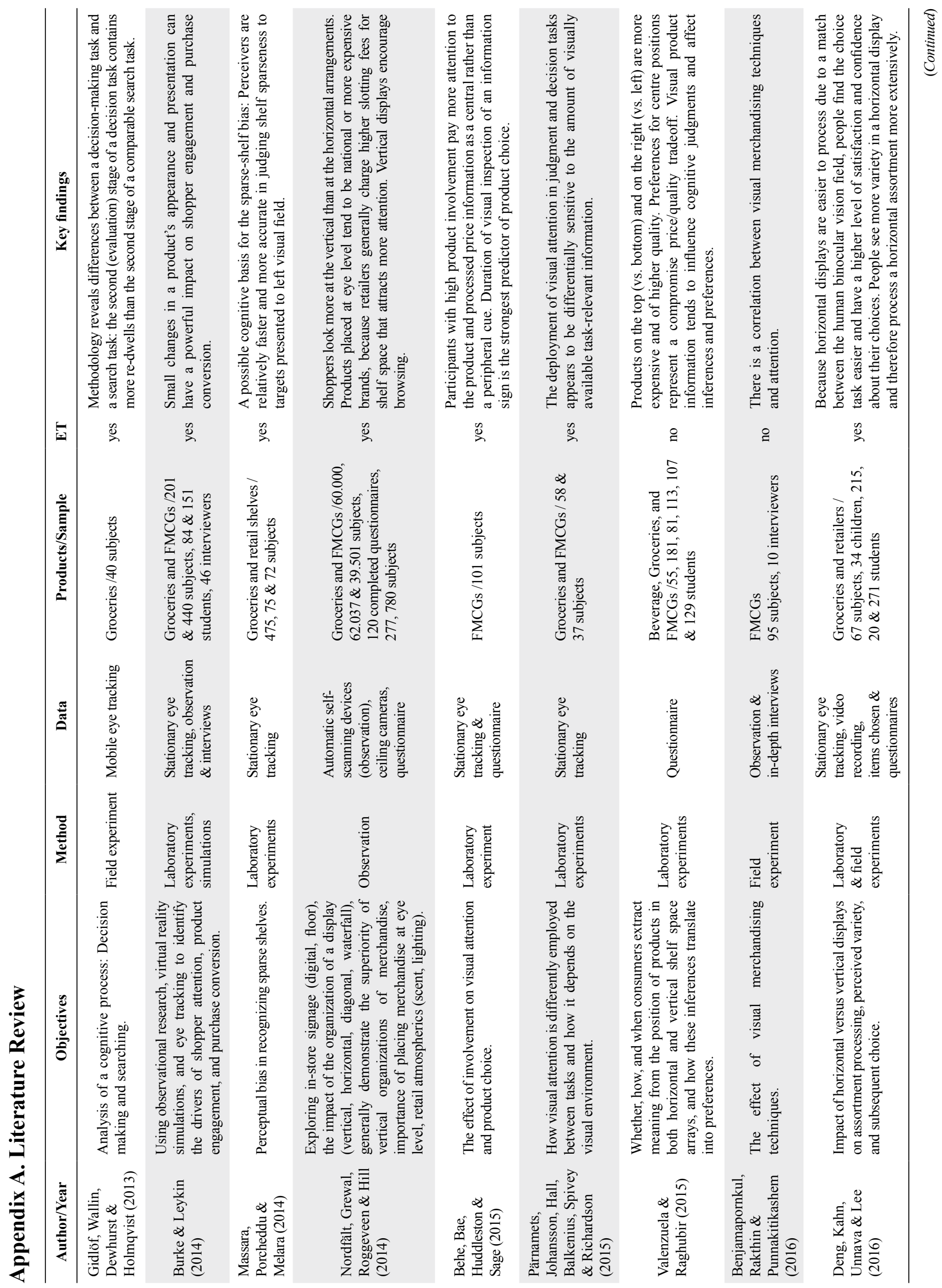




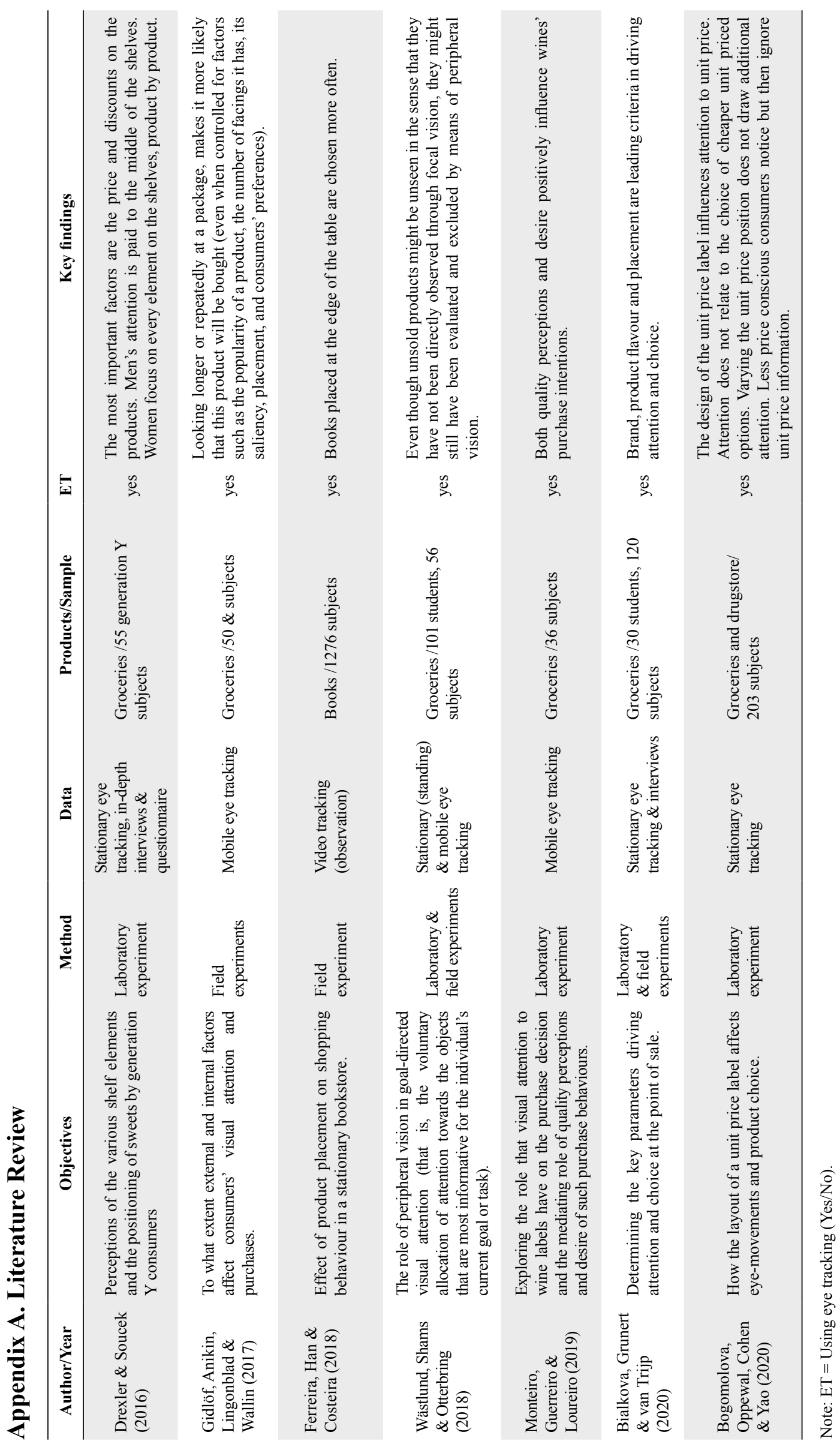




\section{Appendix B. Matching SKUs and Shelf Positions}

Research question RQ1 focuses on the attention generated as a function of horizontal and vertical shelf positions. In accordance with the literature and reduction of model complexity, this research distinguishes between three horizontal and four vertical positions resulting in 12 different slots. In general, however, there is not a perfect concordance between SKUs presented in a shelf and these slots, which requires matching. We demonstrate this procedure for boxed tea (cf. Figure 3).

The size of the packaging for tea allowed for eight (vertical) shelf boards (two packages could be stacked on a board) and six (horizontal) packages per board. The supermarket distributed six different brands of tea offered in 4 different flavours. Following van der Lans et al. (2008) and common practice in this store, flavours (fruit, green, herbal, black tea) were arranged horizontally. The demand for fruit and black tea was higher than the demand for green and herbal tea; therefore, the former flavours received two, the latter one horizontal slot(s). The order of the flavours was determined by chance. Given this choice, brands were located approximately at the same vertical position (determined by random sequencing). Finally, some degrees of freedom remained with regard to the number of facings $(2,4$ or 8$)$ and again, assignment was carried out randomly. As a result, we refer to Figure 3 and Table B1.

Only for a few cases (for example F6) there is a perfect match between SKU and granularity of slots as used in model (1). The third column of Table B2 presents the matching coefficients, i.e., the share of a slot a certain SKUs takes; please note that a SKU might belong to two different slots (e.g., F2). Success variables, determined for a certain SKU, i.e. AOI, were multiplied by these matching coefficients to fit the model's granularity.
Table B2. Correspondence Between SKUs and Slots As Used in Model (1)

\begin{tabular}{|c|c|c|c|c|}
\hline SKU & $\begin{array}{c}\text { Number of } \\
\text { facings }\end{array}$ & $\begin{array}{l}\text { Matching } \\
\text { coefficient }\end{array}$ & $\begin{array}{c}\text { Horizontal } \\
\text { position }\end{array}$ & $\begin{array}{l}\text { Vertical } \\
\text { position }\end{array}$ \\
\hline F1 & 4 & 0.5 & \multirow{7}{*}{ left } & top \\
\hline \multirow{2}{*}{ F2 } & 4 & 0.5 & & top \\
\hline & 4 & 0.5 & & eye \\
\hline F3 & 4 & 0.5 & & eye \\
\hline F4 & 4 & 0.5 & & touch \\
\hline F5 & 4 & 0.5 & & touch \\
\hline F6 & 8 & 1 & & bottom \\
\hline B1 & 8 & 1 & \multirow{6}{*}{ centre } & top \\
\hline B2 & 4 & 0.5 & & eye \\
\hline B3 & 4 & 0.5 & & eye \\
\hline B4 & 4 & 0.5 & & touch \\
\hline B5 & 4 & 0.5 & & touch \\
\hline B6 & 8 & 1 & & bottom \\
\hline H1 & 2 & 0.25 & & top \\
\hline $\mathrm{H} 2$ & 2 & 0.25 & & top \\
\hline H3 & 2 & 0.25 & & eye \\
\hline \multirow{2}{*}{$\mathrm{H} 4$} & 2 & 0.25 & right & eye \\
\hline & 2 & 0.25 & & touch \\
\hline H5 & 2 & 0.25 & & touch \\
\hline H6 & 4 & 0.5 & & bottom \\
\hline G1 & 2 & 0.25 & \multirow{7}{*}{ right } & top \\
\hline \multirow{2}{*}{ G2 } & 2 & 0.25 & & top \\
\hline & 2 & 0.25 & & eye \\
\hline G3 & 2 & 0.25 & & eye \\
\hline G4 & 4 & 0.5 & & touch \\
\hline G5 & 2 & 0.25 & & bottom \\
\hline G6 & 2 & 0.25 & & bottom \\
\hline
\end{tabular}

Table B1. Tea Shelf Used in Field Study I - Schematic Representation

\begin{tabular}{|c|c|c|c|c|c|}
\hline $\begin{array}{c}\text { horizontal } \rightarrow \text { / vertical } \downarrow \\
\text { position }\end{array}$ & Left & Centre & \multicolumn{2}{|c|}{ Right } & \\
\hline Top level & $\mathrm{F} 1^{(*)}$ & $\mathrm{B} 1$ & $\mathrm{H} 1$ & G1 & Brand 1 \\
\hline \multirow{2}{*}{ Eye level } & $\mathrm{F} 2$ & B2 & H3 & G2 & Brand 2 \\
\hline & F3 & B3 & $\mathrm{H} 4$ & G3 & Brand 3 \\
\hline Touch level & F5 & B5 & H5 & G4 & Brand 4 \\
\hline \multirow{3}{*}{ Bottom level } & \multirow{2}{*}{ F6 } & \multirow{2}{*}{ B6 } & \multirow{2}{*}{ H6 } & G5 & Brand 5 \\
\hline & & & & G6 & Brand 6 \\
\hline & Fruit tea & Black tea & $\begin{array}{l}\text { Herbal } \\
\text { tea }\end{array}$ & $\begin{array}{l}\text { Green } \\
\text { tea }\end{array}$ & $\begin{array}{c}\leftarrow \text { flavour of tea } \\
\uparrow \text { tea brand }\end{array}$ \\
\hline
\end{tabular}

(*) letter referring to flavour, number referring to brand. 